\section{First-class products, training and support}

Having pioneered the original All-On-4 treatment concept, Nobel Biocare remains dedicated to providing first-class products, training and support for clinicians.

The All-On-4 treatment concept offers a highly predictable and successful solution for fully, or soon-to-be fully edentulous patients. Extensive clinical study has found accumulative survival rates of $97.6-100 \%$ for implants three to four years after placement, ${ }^{1,2}$ 98.4-99.7\% survival after four to five years ${ }^{3}$ and an impressive $94.8-98 \%$ survival rate between five and ten years after surgery. ${ }^{1,2}$

For practitioners looking to get started with the All-On-4 treatment concept, or those wishing to take their skills to the next level, Nobel Biocare offers a free e-book containing a wealth of information and advice to help you achieve the best results in a safe and efficient way. Helping you identify eligible patients, enhance your treatment planning and avoid common challenges, the e-book is free to download for all from info.nobelbiocare. com/int/en/all-on-4-ebook.

For more information, contact Nobel Biocare on 02087563300 or visit www.nobelbiocare.com.

1. Pomares Puig C. A retrospective clinical study of edentulous patients rehabilitated according to the All on Four or the All on six immediate function concept. Eur J Oral Implantol 2009; 2: 115-124.

2. Agliardi E, Francetti L, Romeo D, Del Fabbro M. Immediate rehabilitation of the edentulous maxilla: preliminary results of a single-cohort prospective study. Int J Oral Maxillofac Implants 2009; 24: 887-895.

3. Agliardi E, Panigatti S, Clericò M, Villa C, Malò P. Immediate rehabilitation of the edentulous jaws with full fixed prostheses supported by four implants. Interim results of a 5 -year single cohort prospective study. Clin Oral Implants Res 2010; 21: 459-465.

\section{Looking for tax efficient investments?}

Conradi Morrison \& Co specialises in assisting all dentists in practice and associates and lecturers. They can advise on all financial and accounting matters such as personal tax, practice tax, formation of companies etc.

Dentists who are looking for a tax efficient investment may well want to consider EIS (Enterprise Investment Scheme) or VCT (Venture Capital Trust). Both these schemes are frequently high risk investments and advice from a qualified independent financial adviser is recommended.

Qualifying investments of up to $£ 1$ million under the Enterprise Investment Scheme and $£ 100,000$ under the Seed Investment Schemes (SEIS) attract income tax relief at $30 \%$ and $50 \%$ respectively. A carry back claim made for $2017 / 18$ investment would reduce tax liability for 2016/17, accelerating a dentist's tax relief.

Disposals of EIS/SEIS investments are also potentially free of Capital Gains Tax. To be exempted, the shares must have been held for a period of three years from the date of issue to the date of sale. Also, if the shares are not held for three years, the income tax relief will not be retained and the tax will be repayable.

You may wish to consider Venture Capital Trusts (VCTs) which are listed companies run by a fund manager and which in turn invest in mainly smaller companies that are not quoted on the Stock Exchange. You are able to invest up to $£ 200,000$ a year $(2017 / 2018)$ in VCTs which will attract income tax relief of up to $30 \%$ and again, are potentially free from CGT, providing you retain the stock for a minimum of three years.

All the investments mentioned above are only suitable for you if you understand that you might receive back less that you invest and you are comfortable with this risk.

These are high risk investments and it is possible that you might lose all the money you invested.

You may prefer investing in another dental practice by buying shares in another company which owns a dental practice or by becoming a partner. In either case, if you do it correctly, you should remove the funds you have invested from your Estate in respect of Inheritance Tax when you die.

Conradi Morrison \& Co would be very glad to meet you and discuss the possibility of tax planning in your business or for you personally.

Call 01322278188 to arrange a meeting at the Dartford office or over the phone or by Skype.

\section{Easy, effective prophylaxis}

Young Dental, the product line for professional dental cleaning, presents new polishing cups, disposable prophy angles as well as pastes for polishing and the removal of discolorations. They are so effective thanks to the remarkable efficiency of baking powder, an excellent brightening effect, a neutral $\mathrm{pH}$ value and they are less abrasive than comparable products.

The 'Mint' and 'Berry' flavoured pastes are vegan, as well as sugar- and gluten-free. They are available in colourful single doses and are therefore easy to identify. The accompanying, sterilisable holder simplifies holding the paste while polishing.

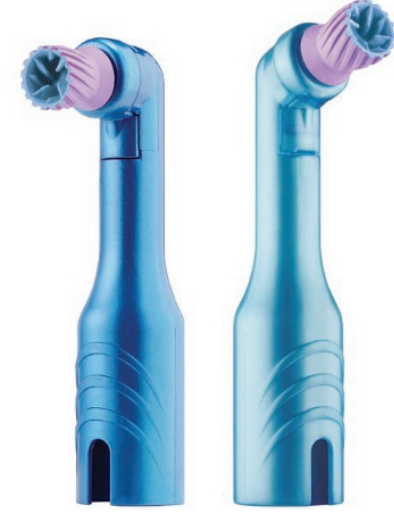

Disposable Prophy Angles by Young Dental make dental polishing more convenient because they have a small, round head and are designed to be particularly narrow, granting the therapist greater visibility and accessibility. The single-use products reduce the risk of infection and save time and costs as no sterilisation or preparation is required and the handpiece is less susceptible to wear and tear. The two-coloured DPAs in the Elite Cup and Petite Web Cup designs, either in straight design or with ergonomic 17 degree contrangle, help to reduce the muscle fatigue.

The Young Dental Prophy Cups are made of special in-house rubber, offering greater flare, reducing splatter and helping achieve an excellent polishing result. The two-coloured cups come in various lengths and degrees of hardness, from firm to extra soft. They are free from latex and available with either a latch/ RA or screw type attachment. Five different designs are offered, so that the user can meet patients' individual requirements. The Elite-Cup also has additional external ridges, which aid in the polishing of the interdental spaces. The cups are individually blister packed to avoid cross-contamination.

www.youngdental.eu 